\title{
THE NATURAL HISTORY OF CORONARY DISEASE
} A CLINICAL AND EPIDEMIOLOGICAL STUDY

\author{
BY \\ JOHN A. RYLE AND W. T. RUSSELL \\ From the Institute of Social Medicine, Oxford \\ Received June 12, 1949
}

Since William Heberden wrote his classic account of angina pectoris in 1768 and Edward Jenner, in a letter to him ten years later, suggested the association of the syndrome with disease of the coronary arteries, the subject has continued to claim the interest and attention of physicians in each succeeding generation. Taking this country alone and excluding living authorities, we have only to recall such names as Latham, Clifford Allbut, Osler, Mackenzie, and Lewis. Symptomatology, both in their periods and since, has been the chief object of speculation and of study and although, with the aid of a more refined and intimate case-work, the subjective phenomena could even now be accorded a more detailed and accurate portraiture, the general clinical picture has been widely approved. The physiological researches of Lewis and his colleagues have advanced our understanding of the pain which is the central symptom. Morbid anatomy (especially in its bearing upon coronary occlusion as the cause of the status anginosus and succeeding cardiac failure), cardiography and radiography, have all made their contributions. Prognosis, with the assistance of technical aids and in experienced hands, has achieved, perhaps, a slightly better precision. Therapeutics, except insofar as a number of useless remedies have been discarded, have not registered any outstanding gains since Lauder Brunton's advocacy of the nitrites. The course of the disease in individuals and the effects of symptomatic treatment have, in brief, been fairly adequately covered.

The study of the disease in the community, on the other hand-its epidemiology and ætiology-have scarcely as yet received adequate consideration. Where individual studies leave gaps in our knowledge social and statistical enquiry may have a contribution to make.

When Heberden, who had no hospital associations, gave his paper to the Royal College of Physicians his experience of angina pectoris amounted to some
20 cases. When he included the description in his "Commentaries" in 1782, his experience had extended to 100 cases. Osler was admitted to the Fellowship of the Royal College of Physicians before he had seen a case in hospital or private practice. Mackenzie, with all his earlier experience in general practice and later as a leading consultant in cardiology, wrote (as late as 1923) that 380 patients had consulted him for angina pectoris. Today, as Cassidy (1946) remarks, " the modern cardiologist's name is legion" and "he counts his cases by thousands rather than hundreds." On both sides of the Atlantic the steadily rising incidence of coronary disease in recent decades has been noted, and it has been suspected that this trend, as indicated by mortality figures, is not wholly to be explained by such factors as the changing ageconstitution of populations and by improved diagnosis and certification at death.

In connection with ætiology, speculations have been frequently advanced concerning the influence of the manifold stresses inherent in the conditions of life and work that our industrial civilization has imposed, and concerning the possible effects of nicotine. That hereditary predisposition plays some part has long been allowed. The assumption that angina pectoris and coronary occlusion are, in the main, expressive of nothing more than the arterial degenerations that accompany the inescapable process of "ageing" has not seemed satisfactory in the absence of a definition of ageing and in the case of a disease so common at the summit of a man's energies and achievement, and now so frequently recorded in the fifth and sixth decades (i.e. at ages 40-59), not infrequently in the fourth decade (30-39), and sometimes even earlier (20-29). Adherents of the so-called psychosomatic school of medicine-perhaps beause their approach has been too predominantly psycho-analytical and because they have tended to see selected examples rather 
than the general run of cases that pass through the hands of the family practitioner, the physician and the cardiologist-have almost certainly overstressed the influence of specific emotional conflict. Those cardiologists, on the other hand, who have doubted the ætiological contributions of mental stress and fatigue, with or without the addition of the more ordinary types of day-to-day anxiety, may be shown to have erred in another direction and to have attached altogether too little importance to the bodymind relationship and to the exacting circumstances of modern modes of life and work, which are in many respects as different as it is possible to imagine from those enjoyed or endured by our more slowly moving agricultural forebears.

\section{THE SCOPE OF THE ENQUIRY}

The present study falls into two parts. The first is based upon a statistical analysis of material to be found in the Reports of the Registrar-General (covering a recent twenty-five year period) in its bearing upon the deaths from coronary disease in England and Wales. This study has involved correlations with age, sex, social class, and occupation and geographical distributions, and has taken into particular account the secular trend of the disease during the period under review. The second is based upon an analysis of the clinical histories of a series of cases seen by one of us (J.A.R.) during a closely similar period of 23 years in the course of consulting practice.

In this manner, and by pooling our experience, it seemed to us that we could, in some measure, combine the advantages of two of the more important methods of socio-medical enquiry. Statistical surveys with correlations based upon official mortality returns rely for their validities upon the large numbers employed. While recognizing that the original data upon which the figures are based have been subscribed by a host of observers of varying reliability, we may yet accept that there is a sufficient smoothing out of error, by virtue of quantity, to compensate for qualitative inaccuracy. As regards the diagnosis of most cases of fatal angina pectoris and coronary occlusion in the period covered by the statistical survey, there should not have been great difficulties, so familiar had the symptom-picture of the first stage of the disease and, commonly, of the second stage, by then become. Nevertheless, steps were taken, as will be seen, to meet the criticism that the diagnosis of coronary thrombosis or occlusion has been made with increasing frequency throughout the period under review, and that certain vague nomenclatures, such as " myocardial degeneration" (which have long been loosely used in death certi- ficates) must now be giving place to more accurate classifications and thereby accounting in large part for the increased rates of mortality.

A clinical survey, even when conducted in retrospect-given that sufficient attention has been paid to possible personal, familial and habitual influences and to social and occupational factors and to the age at onset of the disease-has some, but only some, of the merits of a planned socio-medical enquiry. As a study in morbidity (and this is especially so in the case of diseases that run a long course) it may be considered as a useful supplement to mortality studies, for these can give no indication of age at the onset of the symptoms or of the conditions of life and work then obtaining, and they cannot, as a rule, attempt correlations with other ætiological factors than sex, social class, occupation, and geography. Nor can they throw light upon the various durations of the disease. As a rule, however, the numbers available for a personal clinical study of this kind are very small by comparison with those required by the statistical epidemiologist and often some necessary evidence is found to have been omitted or recorded in a form unsuitable for abstraction. Conclusions drawn from the physician's numerical analyses must consequently be cautious. The majority of cases in the clinical series were seen on one occasion only; some on two, three or more occasions; a few were seen so often and over such long periods of time as to allow of a growing intimacy both with the manifestations and varied course of the malady and with the affairs and personalities of its victims. An obvious disadvantage of the series relates to the fact that the cases were, inevitably, socially selected. An advantage, on the other hand, may be discerned in the fact that the information was collected by a single observer, and that his interest at the time was concentrated on the whole disease rather than upon any particular aspect of it.

\section{The Statistical Study}

In 1926 the reported deaths from angina pectoris in England and Wales totalled 1,880. In 1945 the number of deaths ascribed to disease of the coronary arteries and angina pectoris was 25,012, of which 16,514 occurred among males and 8,498 among females. During the intervening years the mortality from this cause of death has steadily increased and, in this connection, the comment by the RegistrarGeneral (text for the years 1938-9) is of interest:

"The progressive increase since 1920 in the standardized mortality assigned to coronary disease and angina pectoris continued without a break in 1938 and 1939. In 1920 the rates were 
32 per million for males and 13 for females, and by 1939 they were twelve or thirteen times as great (406 and 153 respectively). To what extent this increase is explained by changing fashion in death certification, leading to transfer of deaths from myocardial and cardiovascular degeneration groups, and to what extent it is real, is difficult to ascertain."

The present study, based on the statistics relating to the period 1921-45, was undertaken with the aim of attempting to shed some light on the increased mortality from coronary disease and to observe its social and geographical distribution in England and Wales and its sex relationship.

If the increment that has ostensibly occurred in the mortality has been obtained at the expense of the myocardial group, it is important that the composition of these groups should be uniform or stable during the period of observation. In the present study the following sub-headings and their attached numerical identification in the list of the International Classification of Causes of Death were adopted as suitable criteria:

\begin{tabular}{|c|c|c|}
\hline \multirow{8}{*}{$\begin{array}{l}\text { Myocardial } \\
\text { group }\end{array}$} & Period & Sub-headings \\
\hline & $\begin{array}{c}1921-30 \\
,\end{array}$ & $\begin{array}{l}\text { Fatty heart } 90(5) \\
\text { Other or unspecified myocardial } \\
\text { diseases } 90(7)\end{array}$ \\
\hline & 10210 & $\begin{array}{l}\text { Arteriosclerosis without record } \\
\text { of cerebral vascular lesion } \\
91 \text { (b) (2) }\end{array}$ \\
\hline & 1931-9 & Myocardial degeneration 93 (b) \\
\hline & " & $\begin{array}{l}\text { Myocarditis not distinguished as } \\
\text { acute or chronic } 93 \text { (c) }\end{array}$ \\
\hline & $"$ & $\begin{array}{l}\text { Arteriosclerosis without record } \\
\text { of cerebral vascular lesion } \\
97 \text { (3) }\end{array}$ \\
\hline & $1940-5$ & $\begin{array}{l}\text { Myocardial degeneration, in- } \\
\text { farction, sclerosis and other } \\
\text { chronic myocarditis } 93 \text { (c) }\end{array}$ \\
\hline & " & $\begin{array}{l}\text { Myocarditis not distinguished as } \\
\text { acute or chronic } 93 \text { (d) }\end{array}$ \\
\hline $\begin{array}{r}\text { Coronary } \\
\text { disease }\end{array}$ & $\begin{array}{l}1921-30 \\
1931-9 \\
\text { and } \\
1940-5\end{array}$ & $\begin{array}{l}\text { Angina pectoris } 89 \\
\text { Diseases of the coronary arteries, } \\
\text { angina pectoris } 94\end{array}$ \\
\hline
\end{tabular}

\section{Secular Trend}

In discussing the secular trend of the mortality from any disease or disease-groups over a long series of years, it is essential to be mindful of difficulties that do arise. These may be listed as follows:

(a) Changing fashion in diagnosis.

(b) Changes in the International Classification of Causes of Death.

(c) The abandonment by the Registrar-General of a priority classification and his acceptance of the sequence as stated by the doctor when more than one cause of death is mentioned on the death certificate.

While allowance has been made by the RegistrarGeneral for the influence of (b) and (c) in statistics published for years since 1931, the impact of (a) remains an unknown quantity. There also exists another influential factor in the trend of the allages mortality, namely the effect of change in the age composition of the population. The extent to which this has occurred, even during the relatively short period under review, is manifest in the following figures indicating the proportional age distribution of the population in 1921 and 1945 .

TABLE I

Changing Age of Population

\begin{tabular}{rr|r|r|r|r|r}
\hline \multirow{2}{*}{ Year } & & \multicolumn{3}{|c|}{ Age groups } & \multirow{2}{*}{ All ages } \\
\cline { 3 - 6 } & & $0-14$ & $15-44$ & $45-64$ & $65+$ & \\
\hline 1921 pop. &. & 29 & 47 & 18 & 6 & 100 \\
1945 ,, &. & 21 & 46 & 23 & 10 & 100 \\
\hline
\end{tabular}

The proportion of the population in the age group 45-64 years increased by nearly 30 per cent, and at age $65+$ by nearly 70 per cent, during this time interval of 25 years. It is possible to make allowance for the influence of the ageing factor on the death-rate by calculating the comparative mortality index. This index, which was devised by Dr. Percy Stocks, "expresses each cause of mortality of each year as a ratio of that of 1938 adopted as the base after adjustment for age differences in the population exposed to risk."

Since the diseases that are being studied occur in adult life, and predominantly after the age of 30 , the index, in the present instance, was calculated for age 35 years and upwards. The results for the period 1921 to 1939 for males and females are shown in Fig. 1 and 2, to which was added, as a matter of interest, the curve of the mortality from arteriosclerosis with a record of cerebral vascular lesion.

The upward direction of each of the curves is quite a definite feature of the graphs, but, for both sexes, the gradient is steepest for coronary disease. If three points of time be taken-1921, 1931, and 1939-the comparative mortality index for coronary disease for males was $0.10,0.47$ and 1.13 ; the corresponding values for females were $0.09,0.42$ and $1 \cdot 08$. The graphs also reveal:

(1) The very close alignment between the trend of the mortality from the myocardial group and arteriosclerosis, particularly for females. 
COMPARATIVE MORTALITY INDEX AT AGE 35+ FOR MALES

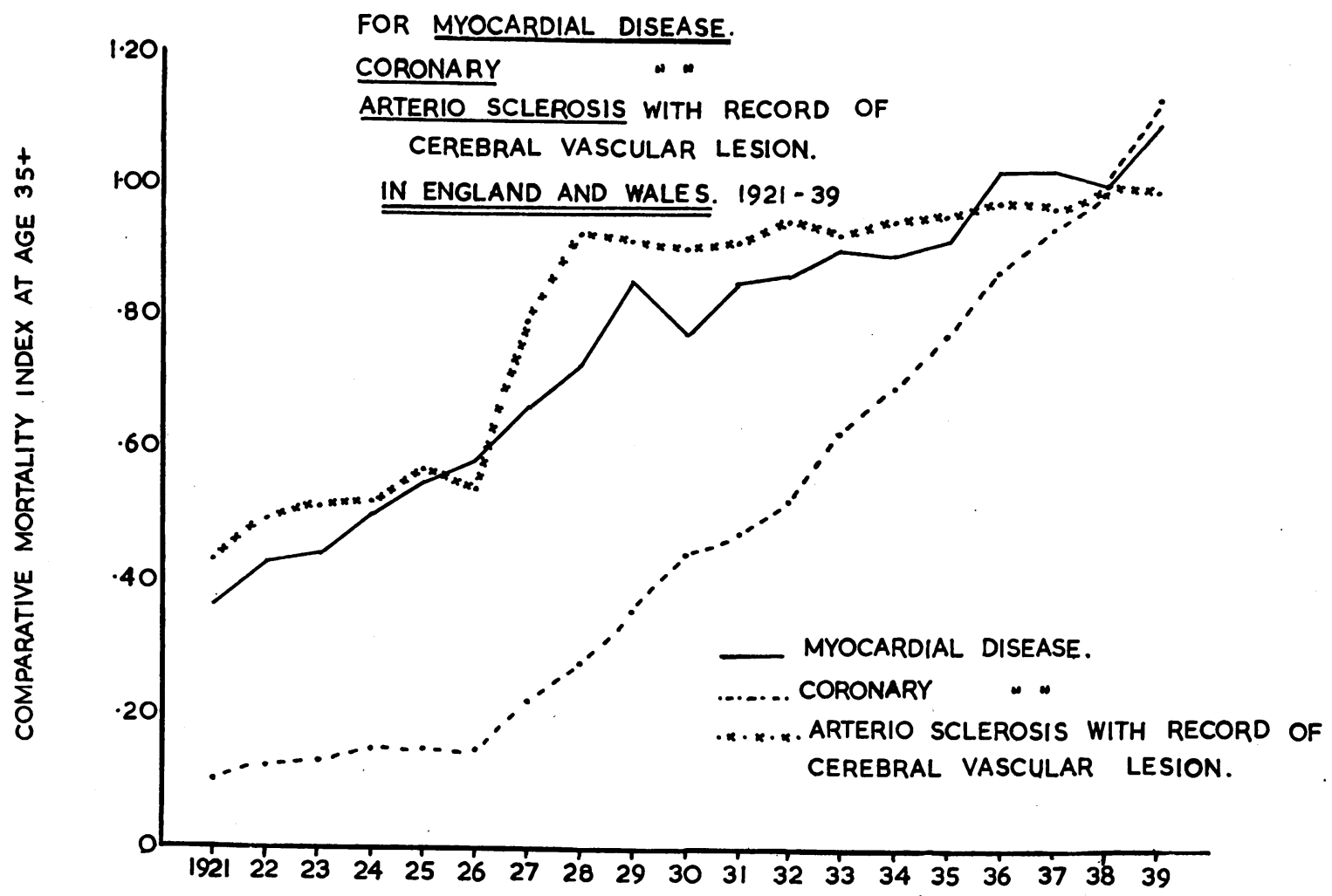

FIG. 1.-Comparative mortality index at age $35+$ for males for myocardial disease, coronary disease, and arteriosclerosis with record of cerebral vascular lesion, in England and Wales 1921-39.

(2) The increment in the death-rate from arteriosclerosis with a record of cerebral vascular lesion between 1926 and 1928, an increase so great and so abrupt as to suggest that it indicates a change in "book-keeping" rather than anything specific in the disease itself.

Since the progressive increase in each of the three causes of death is evident, it is pardonable to make a digression here to ascertain if such increment has been due to a transference of deaths from other forms of circulatory disease. On this particular issue the following statistics, published by the Registrar-General in the text of the report for the years 1938-9, are instructive. As regards the male mortality, which is the more important, the increment in the death-rates at ages when circulatory disease is classified into two groups, $\mathbf{A}$ and $\mathbf{B}$, was as shown in Table II.

The figures suggest that some transference may have occurred from B to A, but certainly not sufficient to account for the vast increase observable in the latter. To quote the Registrar-General: "Such
TABLE II

INCREASE (+) OR DECREASE (-) IN RATES PER MILLION FROM 1921-30 TO 1939

\begin{tabular}{c|c|c}
\hline Age group & $\begin{array}{c}\text { (A) } \\
\text { Coronary. } \\
\text { Myocardial. } \\
\text { Arteriosclerosis. } \\
\text { Senility }\end{array}$ & $\begin{array}{c}\text { (B) } \\
\text { Valvular and } \\
\text { other heart } \\
\text { disease }\end{array}$ \\
\cline { 2 - 3 } & Males & Males \\
\hline $45-$ & +581 & -284 \\
$50-$ & +1377 & -369 \\
$55-$ & +2420 & -737 \\
$60-$ & +4110 & -1477 \\
$65-$ & +6114 & -2806 \\
$70-$ & +9674 & -3994 \\
$75+$ & +20856 & -5861 \\
\hline
\end{tabular}

transfer could, however, account for only a fraction of the increase registered amongst males for degenerative diseases affecting the myocardium and vascular system." The position would thus seem 
COMPARATIVE MORTALITY INDEX AT AGE 35+ FOR FEMALES FOR

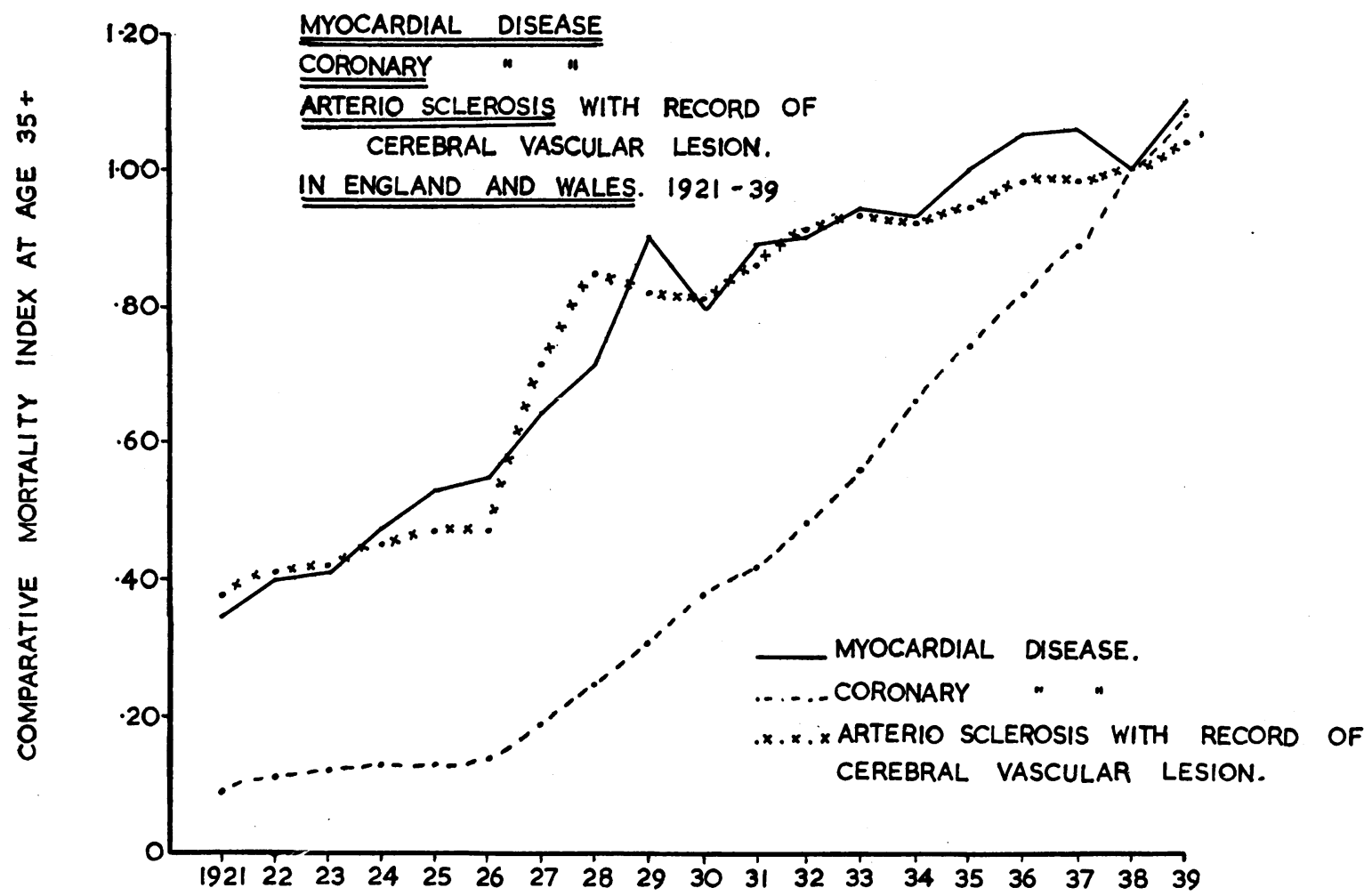

FIG. 2.-Comparative mortality index at age $35+$ for females for myocardial disease, coronary disease, and arteriosclerosis with record of cerebral vascular lesion, in England and Wales 1921-39.

to be that, up to 1939 , coronary and myocardial disease were each increasing but not doing so mainly at the expense of the residual circulatory forms, and that the rate of increase was much greater in respect of the mortality from coronary disease. But the similarity in the trend of the respective mortality of the two disease-groups ended in 1939 because the subsequent statistical experience, especially since 1941, has been entirely different. The-comparative mortality index for coronary disease in males in 1945 , was 1.43 , or 43 per cent greater than the death-rate in 1938, whereas the myocardial index was 0.76 , or 24 per cent in defect of the 1938 standard. Similarly for females, the 1945 index for coronary mortality was $1 \cdot 38$, or 38 per cent greater than that in 1938 , but the myocardial ratio was 0.80 , or 20 per cent in defect. It would thus seem that there has been either (a) a real decrease in myocardial mortality, or (b) a change in certification, observable since 1940; and that some deaths, previously attributed to myocardial causes, are now ascribed to one or other of the circulatory forms. The divergence in point of time is too abrupt and sudden to indicate (a); and (b) would therefore offer the more sensible explanation.

\section{Mortality According to Age}

(i) Coronary disease. While a picture of mortality based on a rate or ratio for combined ages, even though such values be adjusted for effects of ageing of the population, is informative, it nevertheless lacks the clarification that a study of age-specific rates of mortality can afford. For this reason the average annual death-rates in age groups from coronary disease in the periods 1921-30, 1931-39 and 1940-45 (excluding 1944), and the percentage increments relative to the first epoch, are given in Table III. The death-rates at ages in the periods 1921-30 and 1931-39 were adjusted (by the application of conversion ratios) so as to make them comparable with those based on the revised classification that became operative in and after 1940 . In the interpretation of the results it is essential to bear in mind that the time intervals are different, 
TABLE III

The Death-Rates per Million of Population in Age Groups for Coronary Disease in England and Wales for Certain Periods

Coronary Disease

\begin{tabular}{|c|c|c|c|c|c|c|c|c|c|c|c|c|}
\hline \multirow{3}{*}{ Age group } & \multicolumn{6}{|c|}{ Males } & \multicolumn{6}{|c|}{ Females } \\
\hline & \multicolumn{3}{|c|}{ Period } & \multicolumn{3}{|c|}{$\begin{array}{l}\text { Percentage compared } \\
\text { with 1921-30 }\end{array}$} & \multicolumn{3}{|c|}{ Period } & \multicolumn{3}{|c|}{$\begin{array}{l}\text { Percentage compared } \\
\text { with 1921-30 }\end{array}$} \\
\hline & $1921-30$ & $1931-9$ & $1940-5$ & $1921-30$ & 1931-9 & $1940-5$ & $1921-30$ & $1931-9$ & $1940-5$ & $1921-30$ & 1931-9 & $1940-5$ \\
\hline $\begin{array}{l}35- \\
40- \\
45- \\
50- \\
55- \\
60- \\
65- \\
70- \\
75+\end{array}$ & $\begin{array}{r}16 \\
37 \\
75 \\
147 \\
266 \\
439 \\
653 \\
829 \\
913\end{array}$ & $\begin{array}{r}46 \\
124 \\
282 \\
576 \\
963 \\
1523 \\
2247 \\
3067 \\
3735\end{array}$ & $\begin{array}{r}69 \\
206 \\
466 \\
916 \\
1571 \\
2380 \\
3417 \\
4403 \\
5582\end{array}$ & $\begin{array}{l}100 \\
100 \\
100 \\
100 \\
100 \\
100 \\
100 \\
100 \\
100\end{array}$ & $\begin{array}{l}288 \\
335 \\
376 \\
392 \\
362 \\
347 \\
344 \\
370 \\
409\end{array}$ & $\begin{array}{l}431 \\
557 \\
621 \\
623 \\
591 \\
542 \\
523 \\
531 \\
611\end{array}$ & $\begin{array}{r}4 \\
8 \\
16 \\
34 \\
65 \\
136 \\
-242 \\
339 \\
437\end{array}$ & $\begin{array}{r}12 \\
24 \\
53 \\
117 \\
243 \\
510 \\
897 \\
1338 \\
1960\end{array}$ & $\begin{array}{r}16 \\
36 \\
86 \\
186 \\
397 \\
771 \\
1446 \\
2149 \\
3019\end{array}$ & $\begin{array}{l}100 \\
100 \\
100 \\
100 \\
100 \\
100 \\
100 \\
100 \\
100\end{array}$ & $\begin{array}{l}300 \\
300 \\
331 \\
344 \\
374 \\
375 \\
371 \\
395 \\
449\end{array}$ & $\begin{array}{l}400 \\
450 \\
538 \\
547 \\
611 \\
567 \\
598 \\
634 \\
691\end{array}$ \\
\hline & & & & & & & & & & & & \\
\hline
\end{tabular}

being approximately ten years between the first and second epoch and approximately seven years between the second and third. Broadly speaking the statistical pattern for both sexes is similar. Between age 40 and 75 years there was an increment of approximately 250 per cent in the mortality in each of the intervening age groups in 1931-9 as compared with 1921-30. The increase continued and in 1941-5 ultimately amounted to approximately 450 per cent. The statistics also indicate that in middle age, 40-55 years, the male death-rate was increasing more rapidly than that for females, whereas in old age the position was reversed. Since, on the whole, there has been a fairly uniform increase in the mortality throughout life, the increment which has occurred in middle age being not very dissimilar from that for older people, it is extremely unlikely that transference of deaths from " old age " affords an adequate explanation of the increased mortality from coronary disease.

(ii) Myocardial disease. The relevant statistics for myocardial disease are stated in Table IV. Here again there is a close agreement in the statistical experience of the two sexes. Between age 40 and 65 the rates increased approximately 50 per cent for both males and females in 1931-9 as compared with those in the initial period; subsequently, they decreased, with the result that in 1940-5 the ultimate excess, except at age $75+$, was of the order of 30 per cent for males and 20 per cent for females.

Transference of Myocardial Deaths

Attention has been previously drawn to the decline in the comparative mortality index, at age 35 years and upwards, for myocardial disease since
1941. It would appear from Table IV that each age was affected, as the death-rate in every age group in the period 1940-5 is lower than the corresponding value in 1931-9. This fact would seemingly indicate that some deaths previously certified as due to this cause are now ascribed to one or other of the forms of circulatory disease. The relevant questions then arise; is it possible:

(1) To estimate the extent of this transposition?

(2) To ascertain if the coronary disease mortality has been credited with the transfer?

The clinical features of coronary thrombosis were first clearly presented in England by McNee (1925). A lapse of fifteen years before the acceptance of a more precise classification of causes of cardiac deaths became general would not be remarkable. The following procedure was adopted to provide an answer for which no exact precision is claimed, but only a fair degree of approximation. It was assumed that the age-specific death-rates for both myocardial and coronary disease increased linearily during the period 1931-9, which means that the equation of a straight line describes their course during the years in question. The constants obtained from these linear equations for each age group were utilized to forecast the expected agespecific death-rates in 1945. Admittedly, extrapolates obtained from such limited experience, and for so relatively wide an interval of time, are not entirely satisfactory. Nevertheless, the procedure offers the only adequate method of approach. The comparison of the actual and predicted rates of mortality at ages (adjusted for change in classification) for each of the two causes of death is made 
TABLE IV

The Death-Rates per Million of Population in Age Groups for Myocardial Disease in England AND WALES For Certain EPOChS Myocardial Disease

\begin{tabular}{|c|c|c|c|c|c|c|c|c|c|c|c|c|}
\hline \multirow{3}{*}{ Age group } & \multicolumn{6}{|c|}{ Males } & \multicolumn{6}{|c|}{ Females } \\
\hline & \multicolumn{3}{|c|}{ Period } & \multicolumn{3}{|c|}{$\begin{array}{l}\text { Percentage compared } \\
\text { with 1921-30 }\end{array}$} & \multicolumn{3}{|c|}{ Period } & \multicolumn{3}{|c|}{$\begin{array}{l}\text { Percentage compared } \\
\text { with 1921-30 }\end{array}$} \\
\hline & 1921-30 & 1931-9 & $1940-5$ & 1921-30 & $1931-9$ & $1940-45$ & $1921-30$ & $1931-9$ & $1940-5$ & $1921-30$ & $1931-9$ & $1940-5$ \\
\hline $\begin{array}{l}35- \\
40- \\
45- \\
50- \\
55- \\
60- \\
65- \\
70- \\
75+\end{array}$ & $\begin{array}{r}55 \\
116 \\
322 \\
628 \\
1254 \\
2617 \\
5392 \\
10,213 \\
23,777\end{array}$ & $\begin{array}{r}97 \\
214 \\
462 \\
1003 \\
1932 \\
3935 \\
7725 \\
15,904 \\
40,988\end{array}$ & $\begin{array}{r}70 \\
152 \\
343 \\
796 \\
1725 \\
3471 \\
7027 \\
13,922 \\
39,153\end{array}$ & $\begin{array}{l}100 \\
100 \\
100 \\
100 \\
100 \\
100 \\
100 \\
100 \\
100\end{array}$ & $\begin{array}{l}176 \\
185 \\
143 \\
160 \\
154 \\
150 \\
143 \\
156 \\
172\end{array}$ & $\begin{array}{l}127 \\
131 \\
107 \\
127 \\
137 \\
133 \\
131 \\
136 \\
165\end{array}$ & $\begin{array}{r}48 \\
91 \\
242 \\
473 \\
917 \\
1928 \\
3880 \\
7672 \\
20,508\end{array}$ & \begin{tabular}{|r|}
101 \\
184 \\
365 \\
706 \\
1376 \\
2928 \\
6008 \\
12,520 \\
36,382
\end{tabular} & $\begin{array}{r}65 \\
122 \\
269 \\
539 \\
1091 \\
2371 \\
5067 \\
11,144 \\
35,099\end{array}$ & $\begin{array}{l}100 \\
100 \\
100 \\
100 \\
100 \\
100 \\
100 \\
100 \\
100\end{array}$ & $\begin{array}{l}210 \\
202 \\
151 \\
149 \\
150 \\
152 \\
155 \\
163 \\
177\end{array}$ & $\begin{array}{l}135 \\
134 \\
111 \\
114 \\
119 \\
123 \\
131 \\
145 \\
171\end{array}$ \\
\hline
\end{tabular}

in Table V. For coronary disease it will be seen that, for each age group, with one single exception (45-50 for males), the expected death-rate is greater than the actual death-rate. For males, apart from age $70+$, the excess at the other ages is of the order of 10 per cent. For females the difference is somewhat greater. Hence it would appear that the mortality from coronary disease is now increasing less rapidly than in the period before the war. As was to be expected from the previous evidence, the gulf between the actual and predicted death-rates in 1945 for myocardial disease is not only much wider but, as will be noted, the disparity is correlated with age for both sexes. Up to age 55 the expected death-rate for males exceeds the actual by nearly 100 per cent. The difference subsequently declines and after age 60 it amounts to approximately 50 per cent. For females the difference is greatest at

TABLE $\mathrm{V}$

The Actual and Expected Death-Rate per Million of Population in Age Groups from Coronary and Myocardial Disease in England AND Wales in 1945

Coronary Disease

\begin{tabular}{|c|c|c|c|}
\hline \multirow[b]{2}{*}{ Age group } & \multicolumn{3}{|c|}{ Males } \\
\hline & $\begin{array}{c}\text { Actual } \\
\text { death-rate }\end{array}$ & $\begin{array}{l}\text { Expected } \\
\text { death-rate }\end{array}$ & $\begin{array}{l}\text { Difference as percent- } \\
\text { age of actual } \\
\text { death-rate }\end{array}$ \\
\hline $\begin{array}{l}45- \\
50- \\
55- \\
60- \\
65- \\
70- \\
75+\end{array}$ & $\begin{array}{r}542 \\
1045 \\
1838 \\
2924 \\
4066 \\
5256 \\
6477\end{array}$ & $\begin{array}{r}542 \\
1168 \\
2008 \\
3140 \\
4313 \\
6126 \\
7723\end{array}$ & $\begin{array}{r}0 \\
-12 \\
-9 \\
-7 \\
-6 \\
-17 \\
-19\end{array}$ \\
\hline $\begin{array}{l}70- \\
75+\end{array}$ & \multicolumn{3}{|c|}{ Females } \\
\hline $\begin{array}{l}45- \\
50- \\
55- \\
60- \\
65- \\
70- \\
75+\end{array}$ & $\begin{array}{r}98 \\
234 \\
447 \\
893 \\
1680 \\
2600 \\
3392\end{array}$ & $\begin{array}{r}108 \\
237 \\
517 \\
1039 \\
1850 \\
2787 \\
4390\end{array}$ & $\begin{array}{r}-10 \\
-1 \\
-16 \\
-16 \\
-10 \\
-7 \\
-29\end{array}$ \\
\hline
\end{tabular}

Myocardial Disease

\begin{tabular}{|c|c|c|}
\hline \multicolumn{3}{|c|}{ Males } \\
\hline $\begin{array}{c}\text { Actual } \\
\text { death-rate }\end{array}$ & $\begin{array}{l}\text { Expected } \\
\text { death-rate }\end{array}$ & $\begin{array}{l}\text { Difference as percent- } \\
\text { age of actual } \\
\text { death-rate }\end{array}$ \\
\hline $\begin{array}{r}280 \\
659 \\
1424 \\
3065 \\
6377 \\
12,812 \\
36,250\end{array}$ & $\begin{array}{r}547 \\
1353 \\
2666 \\
5483 \\
9424 \\
19,430 \\
54,681\end{array}$ & $\begin{array}{r}-95 \\
-105 \\
-87 \\
-79 \\
-48 \\
-52 \\
-51\end{array}$ \\
\hline \multicolumn{3}{|c|}{ Females } \\
\hline $\begin{array}{r}197 \\
461 \\
947 \\
2097 \\
4542 \\
10,445 \\
33,517\end{array}$ & $\begin{array}{r}421 \\
838 \\
1524 \\
3378 \\
7024 \\
15,262 \\
47,289\end{array}$ & $\begin{array}{l}-114 \\
-82 \\
-61 \\
-61 \\
-55 \\
-46 \\
-41\end{array}$ \\
\hline
\end{tabular}


TABLE VI

The Actual and "Potential" Deaths per Million of Population in Age Groups in 1945 from Coronary Disease AsSuming the MoRTality has beEn INCREASED by TRANSFer from the Myocardial Group

\begin{tabular}{|c|c|c|c|c|}
\hline \multirow{3}{*}{ Age group } & \multicolumn{4}{|c|}{$\begin{array}{l}\text { Potential death-rate }=\text { expected coronary death-rate plus difference between actual and expected } \\
\text { myocardial death-rate }\end{array}$} \\
\hline & \multicolumn{2}{|c|}{ Males } & \multicolumn{2}{|c|}{ Females } \\
\hline & Actual death-rate & Potential death-rate & Actual death-rate & Potential death-rate \\
\hline $\begin{array}{l}45- \\
50- \\
55- \\
60- \\
65- \\
70- \\
75+\end{array}$ & $\begin{array}{r}542 \\
1045 \\
1838 \\
2924 \\
4066 \\
5256 \\
6477\end{array}$ & $\begin{aligned} 542+267 & =809 \\
1168+694 & =1862 \\
2008+1242 & =3250 \\
3140+2418 & =5558 \\
4313+3047 & =7360 \\
6126+6618 & =12,744 \\
7723+18,431 & =26,154\end{aligned}$ & $\begin{array}{r}98 \\
234 \\
447 \\
893 \\
1680 \\
2600 \\
3392\end{array}$ & $\begin{array}{rr}108+224= & 332 \\
237+377= & 614 \\
517+577= & 1094 \\
1039+1282= & 2321 \\
1850+2482= & 4332 \\
2787+4817= & 7604 \\
4390+13,772= & 18,162\end{array}$ \\
\hline
\end{tabular}

45-50 years-114 per cent-but no undue importance may be given to this value because the mortality at this particular age is low. At the other ages the decline approximates to that for the male sex, with the result that in old age the expected death-rate is roughly 45 per cent in excess of the actual.

Since the "calculated" age-specific death-rates from coronary disease in 1945 are greater than the actual, it would suggest either:

(1) that there has been little or no transference from the myocardial group to this category; or

(2) that coronary disease in itself has decreased and that the high mortality now observable is actually due to a transfer of myocardial deaths.

Hence it is of interest to assess what would have been the position if the transposition had occurred. The most likely magnitude of the transfer would have been the excess of the expected over the actual death-rates from myocardial causes. The addition of this difference to the expected coronary deathrate would yield what we have called the " potential death-rate" from coronary disease in 1945. The result shown in Table VI indicates that if such a change or transfer occurred the coronary death-rate up to age 75 years for males would be doubled and, beyond that age, would be four times its existing size. The alteration in the female mortality would have been even greater.

\section{Sex Ratio}

Although the increment in the mortality from coronary disease has not been dissimilar for the two sexes, the dominance of the male mortality over that for females is excessive, as will be seen in Table VII which shows the male-female sex ratio at the various age groups and, in addition, similar

\section{TABLE VII}

Showing the Sex Ratio $\left(\frac{M}{\bar{F}}\right)$ at Age Groups for Coronary and Myocardial Mortality in England and Wales at Differént Periods

Coronary Disease

\begin{tabular}{c|c|c|c}
\hline Age group & $1921-30$ & $1931-9$ & $1940-3$ \\
\cline { 2 - 3 } 35 & $4 \cdot 0$ & $3 \cdot 8$ & $4 \cdot 3$ \\
40 & $4 \cdot 6$ & $5 \cdot 2$ & $5 \cdot 7$ \\
45 & $4 \cdot 7$ & $5 \cdot 3$ & $5 \cdot 4$ \\
50 & $4 \cdot 3$ & $4 \cdot 9$ & $4 \cdot 9$ \\
55 & $4 \cdot 1$ & $4 \cdot 0$ & $4 \cdot 0$ \\
60 & $3 \cdot 2$ & $3 \cdot 0$ & $3 \cdot 1$ \\
65 & $2 \cdot 7$ & $2 \cdot 5$ & $2 \cdot 4$ \\
70 & $2 \cdot 4$ & $2 \cdot 3$ & $2 \cdot 0$ \\
$75+$ & $2 \cdot 1$ & $1 \cdot 9$ & $1 \cdot 8$ \\
\hline
\end{tabular}

Myocardial Disease

\begin{tabular}{c|c|c}
\hline $1921-30$ & $1931-9$ & $1940-3$ \\
\hline 1.15 & 0.96 & 1.08 \\
1.27 & $1 \cdot 16$ & $1 \cdot 25$ \\
1.33 & $1 \cdot 27$ & 1.28 \\
1.33 & 1.42 & 1.48 \\
1.37 & 1.40 & 1.58 \\
1.36 & 1.34 & 1.46 \\
1.39 & 1.29 & 1.39 \\
1.33 & 1.27 & 1.25 \\
1.16 & $1 \cdot 13$ & $1 \cdot 12$ \\
\hline
\end{tabular}




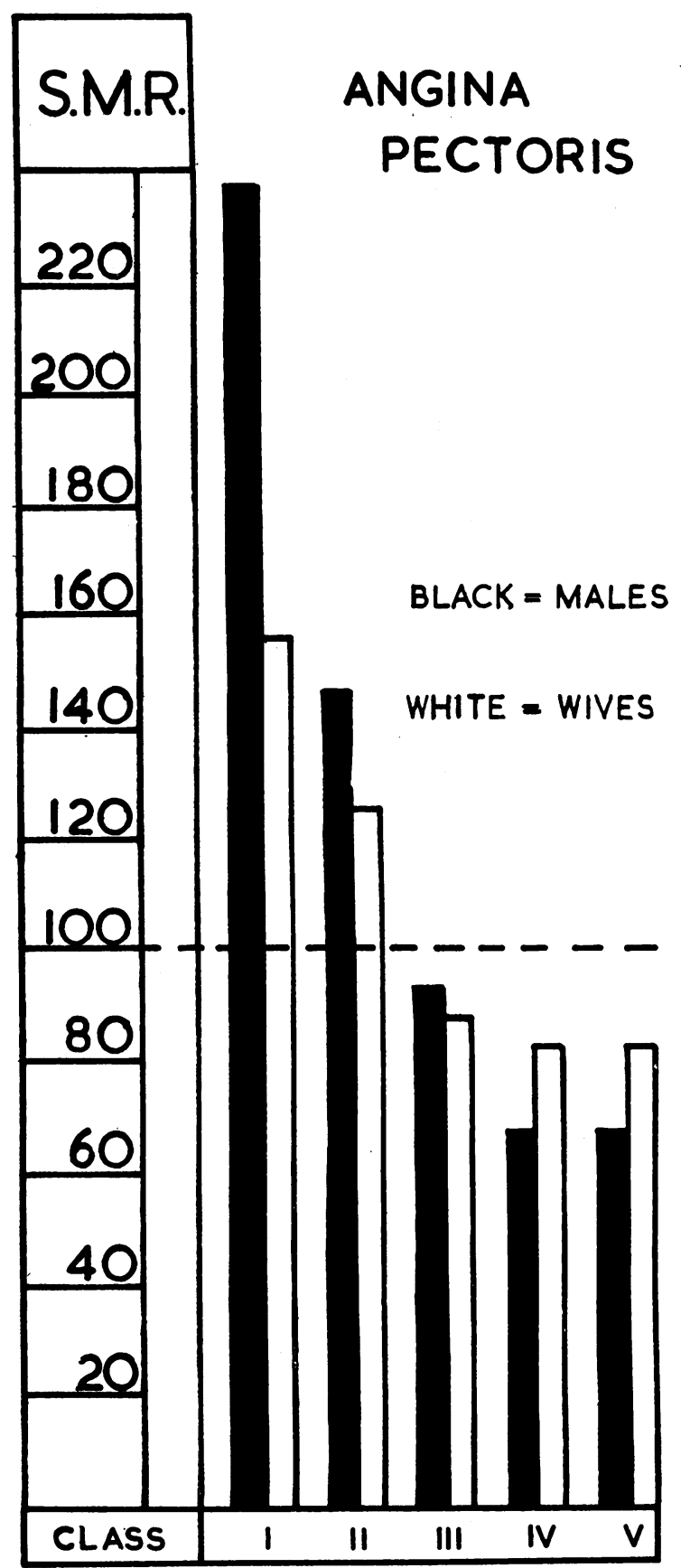

FIG. 3.-Standard mortality ratio from angina pectoris for men divided according to their social class as in the Registrar-General's reports, and for wives. values for the myocardial diseases. For the latter, the male excess, after age 45 , is of the order of 30 per cent, with no definite age association indicated in any of the three time periods. On the other hand, for coronary disease there is a decided relationship with age, observable in each of the three epochs. For example in 1940-5 the male death-rate at age 40-50 was more than 5 times greater than for females; at 55-60 the ratio drops to 4.0 and at $75+$ it is less than 2 .

This negative correlation of the sex ratio for coronary disease with age and the relative absence of any association in the case of myocardial disease suggests the impact of some factor detrimental to males in the causation of coronary disease. The most obvious sex discriminant is an occupational influence and, in this respect, the statistics available in the Registrar-General's Occupational Supplement for 1930-2 are instructive. In this very interesting and valuable report, the Registrar-General published the mortality from various diseases according to five social classes. The constitution of these social classes has so often been described that it is unnecessary at this stage to enlarge on their structure. It is sufficient to state that Class I is largely composed of professional workers, Class III represents skilled artisans and Class V unskilled workers-the two residual groups being intermediate to the contiguous grades. The correlation between the mortality from angina pectoris and social level is depicted in Fig. 3 in which it will be seen that, for both men and wives the decrease in mortality with descent in the social grading is clearly indicated. For males in Class I the mortality is 137 per cent in excess of the average for all males aged 20-65 years. It is 4 per cent in defect for skilled workers, and for unskilled workers the mortality is 33 per cent below the expected or normal value. If the occupations comprising the various social orders are studied separately the comparison is even more strikingly depicted, as will be seen from the mortality ratios in four occupations showing the highest and lowest values respectively (Table VIII).

These results clearly indicate the influence of type of work on the liability to death from coronary disease, since the four occupations having the highest ratios are those requiring not only a high degree of mental activity but also involve considerable anxiety and stress in their performance. For workers at the other end of the scale life is, from the point of view of mental activity, relatively less exacting and it would appear that their risk of dying from coronary disease is much more remote.

Realizing then that social or occupational status is a correlate of the mortality from coronary disease, it was of interest to ascertain if men and wives within 
TABLE VIII

Male Occupations of Highest and Lowest MORTALITY FROM CORONARY DISEASE

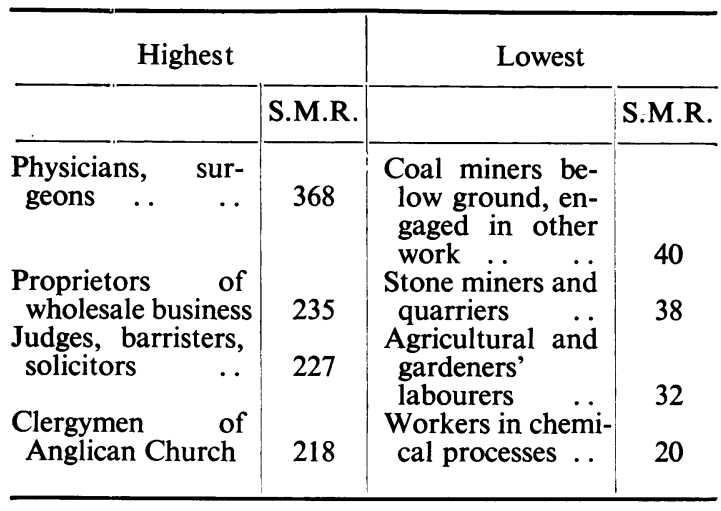

All males $=100$.

(The standardized mortality ratio (S.M.R.) is the percentage ratio of the deaths actually registered in an occupation to those which would be expected to occur if the workers at age periods in that occupation experienced the age-specific death-rates for all males.)

the same social pattern were equally at risk. The sex ratios of their mortality in three age groups for angina pectoris and myocardial disease were evaluated and the results are stated in Table IX. For myocardial disease the variation in the size of the ratio, either according to social gradient or age, is of a slight order, whereas for angina pectoris the position is different; age is a factor, but social class more so. The importance of the latter is most obvious in the age period 45-55 in Social Class I, in which the male death-rate is almost ten times greater than that for wives; for skilled workers (Class III) the sex ratio is five; and it drops to 3 in the lowest social class. Why, it may be asked, is the ratio dominantly male in Social Class $I$ at age 45-55? The most likely answer would seem to be that the workers included therein at this age period are those who have usually reached the peak of their professional careers and are exposed to the maximal strain associated with their particular responsibilities. Mentally, their tempo of life is fast and, as the sex ratio indicates, they are not " masters of their fate."

Cassidy, in his Harveian Oration (loc. cit.), asks the following question: "Is it possible that in the remarkable sex-incidence of coronary disease we may find some clue to ætiology? Can it be that masculinity predisposes one to coronary disease, and that feminity safeguards from it-that perhaps cholesteral metabolism is vitiated by maleness?" In this connection, it would seem important not to overlook the question of occupational influence and the fact that the mortality ratio of male professional workers to male manual workers is far higher than that of men to women.

\section{Geographical Distribution}

Finally, in this epidemiological survey it was of interest to depict the geographical distribution of the mortality from coronary disease throughout the country. A direct approach here is not possible because, although the Registrar-General has published, since 1940, the number of deaths from coronary disease in the several areas of the country, the age and sex composition of the population exposed to risk in these areas is unknown. In the present instance, an attempt was made to override this difficulty by comparing, for the twelve major geographical regions, the actual and the expected number of coronary deaths - the latter being estimated from proportional mortality ratios. The procedure of estimation was as follows. The proportion which the coronary deaths in age groups in England and Wales bear to the deaths from all causes at the corresponding ages was estimated for

TABLE IX

Showing the Sex Ratio $\left(\frac{M}{F}\right)$ of the Mortaltty from Angina Pectoris and Myocardial Disease, according to Social Class in England and Wales in 1930-2

\begin{tabular}{|c|c|c|c|}
\hline \multicolumn{4}{|c|}{ Angina Pectoris } \\
\hline \multirow{2}{*}{ Age group } & \multicolumn{3}{|c|}{ Social Class } \\
\hline & I & III & V \\
\hline $\begin{array}{l}45-55 \\
55-65 \\
65-70\end{array}$ & $\begin{array}{l}9 \cdot 9 \\
4 \cdot 6 \\
5 \cdot 0\end{array}$ & $\begin{array}{l}5 \cdot 3 \\
3 \cdot 4 \\
2 \cdot 4\end{array}$ & $\begin{array}{l}3 \cdot 3 \\
2 \cdot 4 \\
2 \cdot 2\end{array}$ \\
\hline
\end{tabular}

\begin{tabular}{|c|c|c|}
\hline \multicolumn{3}{|c|}{ Myocardial Disease } \\
\hline \multicolumn{3}{|c|}{ Social Class } \\
\hline I & III & V \\
\hline $\begin{array}{l}2.2 \\
1.9 \\
1.9\end{array}$ & $\begin{array}{l}1 \cdot 3 \\
1 \cdot 3 \\
1.4\end{array}$ & $\begin{array}{l}1 \cdot 4 \\
1 \cdot 2 \\
1 \cdot 4\end{array}$ \\
\hline
\end{tabular}


the triennium 1941-3 and the results are shown in Table X.

TABLE $\mathbf{X}$

Ratio of Coronary Deaths per 1000 to those from All Causes at Specific Age Periods

\begin{tabular}{c|c|c}
$\begin{array}{c}\text { Age group. } \\
\text { Years }\end{array}$ & Male & Female \\
\hline-40 & $2 \cdot 6$ & $1 \cdot 0$ \\
$40-$ & 35.0 & $9 \cdot 1$ \\
$45-$ & $55 \cdot 0$ & 14.4 \\
$50-$ & $71 \cdot 5$ & 21.8 \\
$55-$ & $79 \cdot 1$ & 33.4 \\
$60-$ & 78.4 & $41 \cdot 2$ \\
$65-$ & 74.2 & $48 \cdot 0$ \\
$70-$ & 70.0 & $41 \cdot 3$ \\
$75-$ & $47 \cdot 6$ & $33 \cdot 1$ \\
$80+$ & 29.0 & 20.6
\end{tabular}

These percentage ratios were accepted as " standard ratios" and applied to the All Causes deaths at the corresponding ages in each areal unit. On this basis the expected number of coronary deaths in each of the twelve major geographical regions of the country was obtained and then compared with the actual number of recorded coronary deaths in the three-year period 1941-3. Proportional mortality, which is the relationship of two variables, when used irrespective of age and time for comparative purpose, has recognized limitations. Possible allowance has been made for these factors in the present instance, but it is nevertheless advisable to test the validity of the adopted procedure.

There being no published statistics in areal units for coronary deaths prior to 1940 a test was made using nephritis as a criterion. The expected deaths from this disease for the two years 1931-2 were estimated in two ways:

(a) By the method of proportional mortality as previously described for coronary disease, allowance being made for the urban and rural character of the region.

(b) By indirect standardization, i.e. applying death-rates at ages from nephritis in the County Boroughs, Urban and Rural Districts in England and Wales to the populations exposed to risk in the specific areal or regional unit.

The expected number of deaths obtained on each of the two hypotheses were then related to those actually recorded. The test was made on the data for Warwickshire which contains the most populous County Borough-Birmingham-in England and Wales. The results are shown in Table XI. As will be noted the ratios obtained by the two different methods, are in very close accord. Hence it would seem that by using proportional mortality
TABLE XI

Ratio of Actual to Expected Deaths from NePHRITIS Estimated IN Two Ways

\begin{tabular}{c|c|c|c|c|c}
\hline \multirow{2}{*}{ Birmingham } & \multicolumn{3}{|c}{ Warwickshire } \\
\cline { 3 - 6 } \multicolumn{2}{c|}{ C.B. } & \multicolumn{2}{|c|}{ Urban } & \multicolumn{2}{c}{ Rural } \\
\cline { 2 - 6 } M. & F. & M. & F. & M. & F. \\
\hline (a) 82 & 67 & 90 & 110 & 69 & 94 \\
(b) 81 & 65 & 97 & 112 & 64 & 84 \\
\hline
\end{tabular}

in the manner indicated, it is possible to estimate, with some degree of accuracy, the number of deaths from coronary disease that might be legitimately expected to occur in each of the twelve major divisions of the country.

The ratios of the actual and expected number of coronary deaths for males and females during the triennium 1941-3 have been worked out for these areas; both for males and females, there is a definite zoning of the mortality. Greater London has an excess of 21 per cent above the average or expected number for males; next in sequence is the group of residual South-Eastern Counties with an excess of 11 per cent, followed by North I where the actual deaths exceed the expected by 3 per cent. There is a large belt composed of North IV, Midlands I and II and Wales I in which the mortality is approximately 15 per cent below the average. The divergence between the results in Wales is noteworthy. In Wales I (South Wales) the recorded deaths are 15 per cent in defect of the expected number, whereas in Wales II (North Wales) the difference is one of 3 per cent.

The ratios for females are closely correlated with those for males, areas with high or low male mortality being also those in which the female deaths are also either in excess or defect of the expected value. The reason for these apparent geographical disparities in the size of the ratios is not readily apparent. Do they represent a true accounting or are they the resultant effect of differences in the social structure of the populations living in the different area units? It is not possible to give a definite answer owing to lack of appropriate data and it is obvious, from previous evidence, that social stratification is an influential factor in determining the mortality from coronary disease.

\section{The Clinical Study}

General observations. The period covered in this part of the enquiry is approximately 23 years $(1920-42)$, but the majority of the cases were seen 
during a 15 -year period (between 1925-39). The experience was that of a general medical consulting practice. The patients included in the series would thus represent, in the main, Social Classes I and II of the Registrar-General's classification by occupations, with a few from Social Class III. After excluding dubious cases the notes of 243 cases remained; these were primarily classified as angina pectoris (144 cases) or as coronary thrombosis (99 cases). Only 2 cases were accepted in which a history of characteristic pain was lacking. No cases of angina vasomotoria or of so-called " hypertensive failure " (Clifford Allbutt's "cardiac defeat") were included, although high blood pressures must have added a load to hearts embarrassed by coronary disease in a number of cases. No cases were included of aortic valvular disease or aneurysm or of pernicious anæmia. This total of 243 cases of coronary disease represents approximately 1.7 per cent of all new private cases seen in consultation during this period. As no special reasons obtained for regarding the writer (J.A.R.) as a cardiologist, cases of heart disease should not have been referred for an opinion in any undue proportion. It is not known how the proportion would compare with that discoverable in family practices of varying type or locality.

Of the 243 cases in the series 164 were males and 79 females, giving an approximate ratio of M2 : F1. This corresponds closely with the sex ratio revealed by the All Ages Deaths from coronary disease in 1945. Cassidy (loc. cit.), in a more predominantly cardiological practice and in a much larger series of cases of coronary disease, records a ratio of M3.5 : F1. Of the 164 male cases, $97(60 \%)$ were primarily classified as angina pectoris and $67(40 \%)$ as coronary thrombosis. Of the 79 female cases, $47(60 \%)$ were primarily classified as angina pectoris and $32(40 \%)$ as coronary thrombosis. The relative incidence of effort angina and of coronary thrombosis was thus similar in the two sexes. On re-perusing the case-histories, however, it was found that angina pectoris (effort angina) had been preceded by an earlier account of a severe prolonged attack of pain, often lasting two hours or more (but without the more catastrophic picture of a severe coronary lesion) in an appreciable proportion of the cases. While most cases of effort angina probably start as such and may be assumed to be due to coronary sclerosis without occlusion, or even to coronary spasm (in association, commonly, with one or more of the general manifestations of hyperpiesia), it would seem probable that small coronary occlusions (sclerotic or thrombotic), often unrecognized at the time, may not infrequently initiate the liability to effort angina.
In the 144 cases (both sexes), primarily classified as angina pectoris, there was a previous history of a prolonged attack of pain-not necessarily associated with effort-in $15(10 \%)$. In 99 cases (both sexes), primarily classified as coronary thrombosis, there was a preceding history of effort angina in $28(28 \%)$. Subsequent histories of the surviving cases of coronary thrombosis were not available in a sufficient number to allow of an estimate of the frequency with which this accident is followed by effort angina. It is well recognized that in some cases recovery is so far complete as to be followed by neither pain nor dyspnœa on exertion, sometimes for long periods. The above observations do little more than lend support to the common clinical and pathological opinion that effort angina and the status anginosus of coronary occlusion are expressions only of different stages or accidents in the same disease. They also suggest that the course and behaviour of the disease in the two sexes is similar, although its frequency is greater in men. It is clear that the two clinical syndromes, expressing coronary sclerosis and sclerotic or thrombotic occlusion respectively, can legitimately be discussed together in any consideration of epidemiology or of possible ætiological factors.

\section{Age of Onset}

Epidemiological studies of chronic types of disease based upon mortality figures are, as has been indicated, in a measure unsatisfactory in that they can give no account of the age of onset or of the occupation or other circumstances obtaining at the time of inception of the disease. The occupation recorded in a certificate is the last one preceding death. In 149 male cases and 69 female cases in this series it was possible to deduce, from the age of the patient noted at the time of the first examination and from the historical notes, the age at onset with a margin of error probably not exceeding one year.

\section{TABLE XII}

\section{Age of Onset of Coronary Disease} $\begin{array}{ccccc}\begin{array}{c}\text { Age at } \\ \text { onset : }\end{array} & \text { Males (youngest) } & 34 & \text { Females (youngest) } & 35 \\ \text { (oldest) } & 90 & \text { (oldest) } & 83\end{array}$

\begin{tabular}{|c|c|c|c|}
\hline & & $\begin{array}{c}\text { Age distribution at } \\
\text { onset }(\text { males) in } \\
149 \text { cases }\end{array}$ & $\begin{array}{c}\text { Age distribution at } \\
\text { onset (females) in } \\
69 \text { cases }\end{array}$ \\
\hline Under 36 & & .. 2 & 1 \\
\hline & .. & .. & 0 \\
\hline & .. & 12 & 1 \\
\hline & .. & 23 & 7 \\
\hline & $\ldots$ & $\ldots$ & 5 \\
\hline & .. & 23 & 12 \\
\hline & .. & 28 & 19 \\
\hline 65 & $\ldots$ & .. 38 & 24 \\
\hline
\end{tabular}


In 26 per cent of the male cases and 13 per cent of the female cases the age of onset was 50 years or less; in 74 per cent of the male and 87 per cent of the female cases the age of onset was over 50 years. The numbers are small but they suggest that the factors accounting for male preponderance are more operative in the earlier or middle than in the later period of adult life. This assumption is supported by the evidence that in England and Wales in 1946 the deaths from coronary disease amongst males aged 30-50 years constituted 6 per cent of the deaths from all causes in this age group, whereas the proportion for females was only 1.4 per cent. At age 50 years and upwards the corresponding values for males and females were 9 and 5 per cent respectively. Newman (1946) has reported on 50 young cases of coronary occlusion from the British armed forces which came under observation during the second world war. Of these, 39 were fatal (33 dying suddenly), and the diagnosis was established at necropsy. Coronary occlusion without thrombosis was recorded in 29 of the cases, and with thrombosis in 10 . The youngest case was aged twenty and no less than 22 were within the age group 20-29. Of the 50 cases, 45 had been graded "fit" or "I" on joining the Service. There was only one female case in the series, but the ratio of men to women in the Services was in the neighbourhood of 10 or $15: 1$. A further reference to this group will be made in the section dealing with aetiology.

\section{Occupation}

In 100 male cases and 47 female cases at ages 65 or less the profession or trade, if any, was sufficiently clearly indicated to allow of an occupational classification. Of the women 11 were single and of these 5 were gainfully occupied. The married women were classified as " housewives"; four of them were, in addition, gainfully occupied.

\section{TABLE XIII}

Occupations (males, aged 65 or less) (100 cases)

Business (including merchants, managers, stock exchange, shopkeepers, etc.) $\quad$. 39

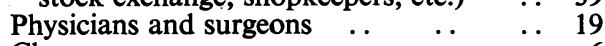

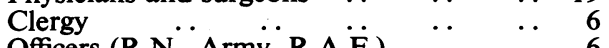

Officers (R.N., Army, R.A.F.) $\quad \ldots \quad$.. $\quad$. 6

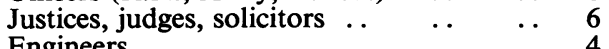

$\begin{array}{lllllll}\text { Engineers } & \ldots & \ldots & \ldots & \ldots & \ldots & 4\end{array}$

The remainder, each item of which scored less than a 4 per cent incidence, belonged to a great variety of professions and trades and included, for example, a peer of the realm; the driver of a hearse; a colonial rancher; a chief railway clerk; a pro- fessor of archæology; and the manager of a skating rink. Of males aged 50 or less at onset (total 39 cases), $12(30 \%)$ were business men, and $11(28 \%)$ physicians or surgeons. It has been previously indicated that according to the standardized mortality ratios published by the Registrar-General for the period 1930-2 the highest value was that for the medical profession (see Table VIII).

\section{TABLE XIV}

OCCuPATions (females, aged 65 or less) (47 cases)

Married women (classified as housewives) Married women (engaged additionally in gainful occupations) ... .. .. Single women (unoccupied or not stated) Single women (gainfully occupied) .. 5

\section{Special Stresses}

In rather more than a third of all the cases (both sexes) there was a clear enough history of occupational, domestic or other stress preceding the onset of symptoms to warrant a consideration of these factors (in concert with the sex and occupational histories) as having a possible bearing upon ætiology. There was a record of " special stress " preceding the onset of symptoms (in most cases over a prolonged period) in 62 male cases and 27 female cases. Of those cases in which there was no record of special stress a considerable proportion were in retirement on account of age. The absence from the casenotes of a history of special stress in these and the remaining cases did not necessarily exclude its occurrence and in some cases the occupation alone made its operations probable. The occurrence of stress is thus under-rather than over-estimated. In a few cases sudden death or a coronary occlusion was shortly preceded by some grave strain or anxiety. Under the heading of special stress were included entries relating to mental overwork or worry in business or the home or in both; heavy public or other responsibilities; or other forms of sustained anxiety. In a few cases intimate knowledge of the patient's affairs was accepted as evidence of stress in the absence of a specific entry relating to it. As "the neurotic temperament" (in distinction from an ambitious or conscientious personality pattern) has sometimes been held to be an ætiological factor, entries bearing on this, or its combination with special stress, were also abstracted (Table XV).

Thus specific records of special stress occurred in at least 38 per cent of males and 34 per cent of females in the whole series. Of 9 (married and single) gainfully occupied women, all may be said to have been working under stress. The 5 occupied single women included: a nurse, still working to within 6 months of onset at the age of 62 ; the headmistress 
TABLE XV

MALES (164 cases)

\begin{tabular}{|c|c|c|c|}
\hline A. $\underset{\text { stress" Special }}{\text { Sp }}$ & $\begin{array}{l}\text { B. Neurotic } \\
\text { temperament } \\
\text { plus " special } \\
\text { stress" }\end{array}$ & $\begin{array}{c}\text { C. Neurotic } \\
\text { temperament } \\
\text { without } \\
\text { record of } \\
\text { "special } \\
\text { stress" }\end{array}$ & $\begin{array}{l}\text { No specific } \\
\text { record }\end{array}$ \\
\hline $60(37 \%)$ & $2(1 \%)$ & $5(3 \%)$ & $97(60 \%)$ \\
\hline \multicolumn{4}{|c|}{ Females ( 79 cases) } \\
\hline $22(28 \%)$ & $5(6 \%)$ & $1(1 \%)$ & $51(65 \%)$ \\
\hline
\end{tabular}

of a big girls' school with many additional public duties and a history of severe mental shock preceding onset at the age of 51 ; a business woman, excessively nervous and conscientious, with onset at 62 ; a religious sister in charge of a large students' hostel, with a strong family history of coronary disease and onset at 50; and a massage and physiotherapy instructor, greatly overworked and with a high sense of duty, with onset at 46 . If the male cases aged 50 and under at the time of onset are taken, there is a specific history of " special stress" in $21(54 \%)$ out of 39 cases; 6 out of 9 female cases (married and single) aged 50 or under at onset $(66 \%)$ gave a history of special stress. The occupations of the single women have been noted above. Of the duties of the modern housewife it may at least be said that her domestic responsibilities are seldom light, that her children, her husband and her home tend to be more seriously considered by her as the generations pass, that she often undertakes additional civic or social responsibilities and, in the social classes studied, commonly has a share in her husband's problems which was denied to the Victorian woman. After age 65 a high proportion of patients were in retirement; some of them were in their seventh or eighth decade; "special stress" would naturally, therefore, have become a less frequent entry. Reliable histories of stress in earlier life are not easily obtained from the elderly, but it was noted as having been operative at some stage in 10 cases $(25 \%)$ out of 41 males, and in 5 cases $(18 \%)$ out of 27 females in the later age groups (i.e. 65 or over).

It would be unwise to infer too much from the above figures. It is evident that stresses, both intellectual and emotional, must generally tend to accumulate towards the zenith of a career and to be fewer at its beginning or towards its close. It must also be allowed that, in the taking of clinical histories, modifiable conditions of life may be more carefully sought for in the case of younger and still occupied subjects. But neither of these considerations compels the exclusion of continuing or recurrent stress as an ætiological factor. The sex and occupational associations reviewed in the statistical study have already drawn attention to its probable importance.

Physical stress. In a few cases golf or tennis was continued into middle or later life, as an addition to an exacting professional career; a few patients had been athletes in their youth; one patient was a blacksmith. There was, however, no strong evidence to suggest that physical over-activity was a factor of comparable importance with mental or emotional over-activity. This is again in accordance with the conclusions to be drawn from the occupational incidence of coronary disease provided by the mortality data, which reveal the relatively low incidence of angina pectoris in manual workers as compared with the professions, to which attention has already been drawn.

\section{Associated Illnesses}

The association of angina pectoris and coronary thrombosis with gall-stones or cholecystitis has often been remarked. The incidence of clinically recognized gall-bladder disease in the general population within the age-period under consideration is not known, but it is doubtful whether it would be found to be as high as 9 per cent in males. On the general experience of hospital and private

\section{TABLE XVI}

\section{AsSociated IllnesSes}

$$
\text { Males (164) Females (79) }
$$

$\begin{array}{llll}\text { Gallstones and cholecystitis } & \ldots & 15(9 \%) & 6(7 \%) \\ \text { Duodenal ulcer } & . . & . & 10(6 \%)\end{array}$

(One case had a history of both duodenal ulcer and gallstones; one of a duodenal and a gastric ulcer.) Other vascular lesions

$\begin{array}{llll}\text { Obesity .. } & . . & \ldots & \ldots\end{array}$ $\begin{array}{lll}\text { Migraine } & \ldots & \ldots\end{array}$ Diabetes or glycosuria

$\begin{array}{ccc} & 7(4 \%) & 6(7 \%) \\ . & 5(3 \%) & 7(9 \%) \\ . & 5(3 \%) & \text { Nil } \\ . . & 4(2 \%) & 4(5 \%)\end{array}$

practice, peptic ulceration has a much higher frequency than gall-bladder disease. The incidence of duodenal and gastric ulcer in male factory populations and some other employments, according to Doll and Avery Jones (personal communication), is between 5 and 6 per cent. A figure of 6 per cent of cases of peptic ulcer in the males of this series is not necessarily, therefore, in excess of anticipation. Migraine has been stated to be common in the histories of anginal cases. The incidence recorded in this series is probably underestimated (a) because a history of it was not particularly sought for, and (b) because it would not, as a rule, be spontaneously mentioned by patients in a request for an account of 
" previous illnesses." If there is more than a chance association between migraine and angina, it is probably related to the fact that the same temperament predisposes both to migraine and angina, that both are noted as commoner in professional workers, and both tend to run in families. The incidence of obesity has also been underestimated in this series, as only the more obvious cases received specific entry. Although weights were routinely recorded, except in bedridden cases, heights were not, so that height-weight ratios could not be determined. It is doubtful whether obesity is causally related to coronary disease, although it is well known that it may add an extra load to an already incommoded heart.

Other vascular disease. Cassidy (loc. cit.) found that hyperpiesis (e.g. a blood pressure of 160 systolic and 100 diastolic or more) was present in nearly 70 per cent of his cases lacking a coincident or recent history of coronary occlusion. In the 150 cases of this series, in which the notes included a clear record, blood pressures of $160 / 100$ or over were recorded at some stage of the disease in 66 cases $(44 \%)$; a further 7 cases (5\%) gave systolic readings of 170 or over with diastolic figures below 100 . Very high readings were frequently recorded in uncomplicated angina pectoris and low readings were by no means the rule after a coronary occlusion. If we accept angina pectoris and coronary occlusion as local manifestations of a more general arterial disease, it might be expected that vascular changes or accidents affecting other parts of the body (e.g. cerebral hæmorrhage or thrombosis, retinal hæmorrhage or peripheral arterio-sclerosis with intermittent claudication) would be a common association. In fact there was, up to the date of the last entry, a history of other local vascular symptoms preceding or succeeding the onset of coronary disease in only 7 male cases $(4 \%)$ and 6 female cases $(7 \%)$. The reasons for local selective actions in arteriosclerosis have yet to be explained. Normal blood pressures do not exclude its presence.

Taking the men and women together there was a record of syphilis in 3 cases, but none showed signs of cardio-aortic syphilis; of coincidental hyperthyroidism in one case; of hypochromic anæmia in 2 cases (one with a coronary thrombosis and the other with effort angina and a history of angina pectoris in four generations); of asthma in 2 cases; of gout in 2 cases; of paralysis agitans in one case; of diverticulitis in one case. There was one case with an earlier history of unilateral pyonephrosis and one of chronic Bright's disease. Four patients had a synchronous carcinoma of the stomach or bowel; one had had a malignant ovarian cyst removed.

\section{Tobacco and Alcohol}

Detailed records of the amount smoked were not kept. Although a large number of men were considerable smokers, in only 2 cases was there a note of "excessive" tobacco consumption; in 4 there was a record of alcoholism; and in 1 of an excessive use of both tobacco and alcohol. Although the majority of men with angina pectoris were smokers, non-smokers are certainly not immune. Among the women of the period and the age-groups reviewed smoking was rare.

\section{Family History}

Family histories, at no time easy to secure in accurate form, are inevitably defective for this further reason-that sympathetic consideration often compels the avoidance of detailed enquiries about cardiac illness and deaths in the parents or other near relatives of persons themselves the subjects of heart disease. The physician is also faced with the difficulty of deciding in the case of coronary disease, whether to include only cardiac cases or all instances of arteriosclerotic illness in the families studied.

Cassidy (loc. cit.) states that "family history played a part" in "almost exactly half his cases," but he supplies no details. For the reasons given, family histories were not consistently enquired into in this series; in the anxious situations accompanying a coronary occlusion they were often not asked for. There were, however, positive family histories of certain or probable coronary disease relating to a parent, a brother or sister, or others in the direct line in 12 male cases (7\%) and in 8 female cases $(10 \%)$. Among the males there was one instance of the same disease in a father and an uncle; one in a father and a brother; one in two brothers. The probable influence of heredity (whether operating through physical, mental, or temperamental predisposing factors or some combination of these) is supported by such histories as the following, which are taken from the present series:

(a) One medical man, who developed his symptoms before the age of 39 , lost a brother from coronary thrombosis in his early thirties.

(b) One religious sister, who developed angina pectoris at 50, gave a history of cardiac deaths in her father, paternal grandfather and grandmother and a paternal great-grandmother and of others in these generations, usually between the ages of 50 and 60 . Her mother's side of the family was healthy.

(c) An unoccupied spinster, developing symptoms at 60 , gave a history of angina or cardiac deaths in her father, and her second and third brothers, and 
of " strokes" in her fourth brother and her second, sixth and eighth sisters.

(d) Twin brothers (probably monozygotic twins), both formerly Army officers of high distinction and mental attainments, and having a remarkable identity of thought and taste, developed coronary disease within a few years of each other.

Of 20 cases (male and female) with positive family histories of angina, coronary thrombosis, or middleage cardiac deaths, $13(65 \%)$ developed symptoms at the age of 50 or less. In some other chronic diseases such as gout, due in part to an inherited factor, symptoms are apt to develop earlier in life where the family history is strong. Whatever the actual contribution of heredity to ætiology may be, the rising mortality from the disease and its occupational associations suggest that extraneous factors must be considered as of major importance.

\section{Prognosis}

A study of the natural history of a disease would be incomplete without a consideration of prognosis. A knowledge of social or group experience has interest in itself and value alike for life assurance and individual assessments. Unfortunately, reliable statistical studies of prognosis are at all times difficult and this is especially so in the more chronic types of illness. There are many circumstances that militate against careful follow-up enquiry in cardiac disease, whether in hospital or consulting practice. While it has always been recognized that angina pectoris is a condition in which precise forecasts, whether in respect of survival or of degrees and durations of improvement are scarcely possible, so many are the variable factors concerned, it would yet be of value if we could discover the mean expectation of life in relation to age of onset, mode of onset, and perhaps to some other factors such as ranges of blood-pressure or the presence or absence of other evidences of arterial disease. It is well known that one man may die in his first attack and that another may live for 20 years or more. John Hunter, notwithstanding that he continued to suffer frequent pain, lived and worked for 20 years after his coronary occlusion at the age of 41 . Cassidy (loc: cit.) records two cases of patients surviving for more than 30 years, and one of a woman who died suddenly at 82 , having experienced effort angina from the age of 30 .

Where coronary thrombosis, as distinct from effort angina, is concerned there was a tendency to take too grave a view of prognosis following the recognition of the syndrome characteristic of the graver episodes which first became familiar in this country after the publication of McNee's paper (1925). While a coronary occlusion accompanied or shortly followed by congestive failure or arrhythmia is commonly succeeded by death in hours, days, weeks, months or at the most a few years, a study of bad attacks in respect of the severity and duration of the pain, but lacking these complications, may reveal a longer expectation of life, sometimes with a resumption of normal activities for considerable periods. With still slighter attacks the outlook may prove to be even better. From the present series three illustrative cases may be selected, each one clinically characteristic and confirmed by cardiographic and subsequent history.

(a) A surgeon, working under a very great physical, mental and emotional stress and a heavy smoker, developed effort angina at the age of 39. Some months later, at the age of 40 , he had an extremely severe coronary thrombosis from which, for a time, it seemed almost impossible that he would recover. There were secondary complications in the form of an extensive pulmonary infarction with a pleural effusion and a prolonged phase of mental confusion. Within two years he was able to return to his hospital duties and thereafter continued them for a further 13 years, to the time of his death although always handicapped by an effort angina and latterly also by intermittent claudication.

(b) A general practitioner, after prolonged hard work and a sad bereavement, had an attack of coronary thrombosis at the age of 45 . Three years previously he had had a cholecystectomy for gallstones. He had otherwise been very healthy and a fine athlete in his youth. He retired from practice early, but was able to do a good deal of steady work in his garden and even for a time to play 36 holes of golf in a day. He remained liable to pain down both arms on walking after meals. He lived happily for 15 years and died during an afternoon nap in his garden.

(c) A masseuse and physiotherapist, the head of a large hospital department and a woman of great energy and with a high sense of duty, had a moderately severe coronary thrombosis at the age of 46 . Subsequently she had symptoms of cholecystitis and at one time some gouty symptoms. She was still working in a private capacity 20 years after the original episode.

These three patients were all under 50 at the time of their first symptoms; all overworked; two were endowed with restless energy. About such younger cases, it may be reasonably argued that they lack the more widespread degenerative changes in the vascular system which develop in the later decades and that the coronary occlusion, in their case, is more in the nature of a local accident. As coronary occlusion commonly affects subsequent efficiency and the expectation of life in an adverse way, the interval that elapses between the first onset of effort 
angina and a first coronary thrombosis or a prolonged attack of pain suggesting a small occlusion, might seem to have some bearing upon the prognosis of the uncomplicated condition. This interval could be estimated in 49 cases only. The approximate duration of uncomplicated angina of effort was estimated in 87 cases.

\section{TABLE XVII}

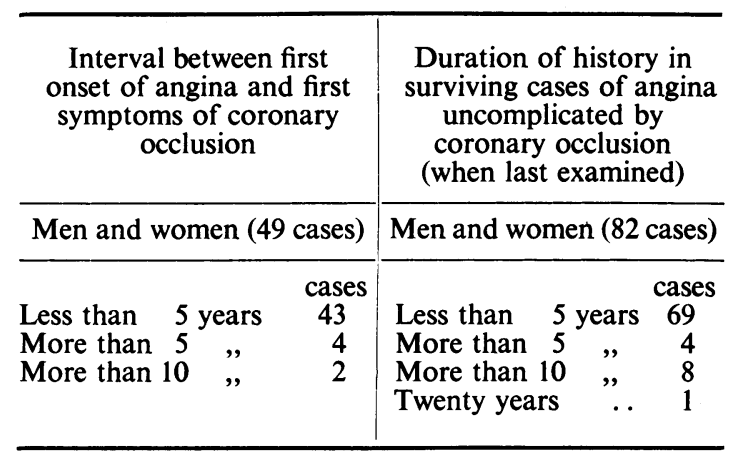

A physician is likely to see an undue proportion of cases in the earlier stages of the disease when they can be referred to him in his consulting room. As, furthermore, the numbers are small and a follow-up enquiry over a further 10 years or more might have been necessary in order to secure the final information in some cases, no conclusion can be drawn from this series with regard to the mean expectation of life at ages in cases of uncomplicated effort angina or of coronary thrombosis. Such conclusions could only be derived from collaborative morbidity studies undertaken by a number of general practitioners covering sufficiently representative social groups and areas of the country and over a sufficient period of time.

Case fatality. According to the data compiled by the Nuffield Bureau of Health and Sickness Records, Oxford, there were 196 patients with coronary disease admitted to the twenty-five hospitals within the Oxfordshire region during the three years 1945-47. The case fatality has been grouped according to age and sex and the All Ages fatality for men and women did not differ appreciably, being 61 and 66 per cent respectively. But at ages under 65 years the rate for males was much higher than that for females. Hence this small sample of hospital statistics, assuming it to be a microcosm of general outside experience, indicates that not only is the disease relatively more concentrated in middleage in males than in females, but also that it is more fatal to them. It should be noted, however, that cases admitted to hospital are likely to include a high proportion of serious cases. There are, in fact, no means at present of ascertaining the case fatality at ages in the general community.

The above observations can only be held to indicate some broad probabilities in the disease as a whole in the groups studied.

\section{Ætiology Reviewed}

Where the predisposing and precipitating factors in a disease are several and there is no known specific agent of extraneous origin-a situation that obtains in many of the chronic endemic diseases of today (such as hyperpiesia and coronary disease, peptic ulcer, the chronic rheumatic diseases and the psychoneuroses)-and where, furthermore, the suspected factors must operate in varying combination and degree in different individuals, it is impossible, in the present state of our knowledge, to assess the full significance and relative importance of any one factor. In favour, however, of each of the five factors-familial predisposition, sex, ageing, certain types of professional employment, and mental and emotional stress-there is, as has been shown in the two main sections of this paper, considerable presumptive evidence. Furthermore, these factors often operate in conjunction:

(a) maleness on account of the occupations which it entails;

(b) the exacting character of sustained mental work accompanying intellectual occupations and posts involving heavy responsibilities;

(c) ageing, through mounting cares and the longer exposure to stress;

(d) the emotional tensions that frequently, on the one hand, accompany business, professional and intellectual life and interruptions to it, and, on the other, are expressions of

(e) the inheritance of an ambitious or conscientious personality pattern.

We have, at present, no reliable evidence bearing upon the association of special physical types. To the physician in his consulting room patients with angina pectoris present no such conformity of pattern as can be observed, for instance, in a high proportion of cases of duodenal ulcer. As in the case of hyperpietics, many anginal subjects are of good physique and have enjoyed excellent health in earlier life; this may have contributed to their energetic habits.

It may be argued, on the summary of the evidence presented, that the older the patient developing coronary disease the more have the ordinary exigencies of the years subscribed to the general and the coronary arterial degeneration; and that the younger the patient the more are we entitled to blame exceptional stress and the general pace and 
fret of life in our modern mechanized world, in some cases with the added influence of familial predisposition. Statistical studies and clinical observations would seem, in the main, to support one another. Heberden's "disturbance of mind" is not to be ignored as a possible ætiological factor in coronary disease. The very fact that any of the more urgent emotions can precipitate anginal pain, and occasionally even a coronary occlusion, should suggest the possibility that repeated emotional disturbance or prolonged anxiety may have a continuing adverse influence on the coronary vessels. But, whatever part the stronger or more suppressed emotions may play, it would also seem, from the evidence here assembled, that sustained mental over-activity is another form of "disturbance of mind" which must be taken into account and considered as capable of affecting the coronary circulation and eventually of causing damage to the arteries and the heart. It is not possible to separate the effects of mental overwork and of the emotions (in the form of ordinary worries) which accompany it, but "the neurotic temperament" had a low incidence in the clinical series. Of all the extraneous factors inimical to hyperpietic subjects, with or without coronary disease, clinical experience, again and again, suggests that mental fatigue and strain and broken sleep are the most outstanding.

The possibility remains that business and the professions tend continually to select from the population those types of person who are most predisposed to the disease. This, however, would scarcely account for the steep rise in incidence and mortality within so short a period as a quarter of a century, and could only partially explain the occupational associations that have been demonstrated. Although it cannot be excluded it does not seem necessary to assume a contribution to male proclivity on the part of the sex hormones, nor is there any suggestion of sex-linked inheritance.

Of the associated diseases recorded in this series none would seem to be causally related, with the possible exception of gall-bladder disease. There would be no sufficient reason to think of a relationship in this instance on the score of its observed frequency, but for the further clinical observation than an acute cholecystitis sometimes closely precedes or succeeds a coronary thrombosis. This association should be worthy of more intimate study.

Tobacco. The fact that the majority of the women were non-smokers and that the disease can occur in male non-smokers, renders the influence of nicotine a doubtful one, although it cannot, as yet, be entirely excluded.

\section{The Youthful Cases}

Separate consideration must be given to cases in the youngest age-group (20-35). Through the kindness of the author of the paper relating to service cases, based on Ministry of Pensions records (Newman, loc. cit.), we have been provided with notes, not included in his account, bearing upon arm of the service, rank, duties and pre-service occupation for the whole group and abstracts of findings at necropsy in 28 cases. With the exception of one medical officer and two men promoted from the ranks during the war all were in the " other ranks" category. There was no indication in the brief records available that "special stress" had been a likely or, at any rate, a sustained experience during service or in civil life. Relatively few (15 out of 50) appear to have been on active combatant service. Most of the cases would have fallen into the Registrar-General's Social Classes IV or V. The ages of the 28 cases examined at necropsy varied from 20-35. In the majority of these arterial changes were so advanced as to suggest that the disease was of some standing and that it had probably started in civil life. The pathological descriptions were not characteristic of syphilitic arteritis. In 6 cases in the whole group the earlier civil occupation might have involved a lead hazard. Reading these records and finding few indications of special occupational stress or other extraneous factor, one might at first feel inclined to reconsider some of the conclusions drawn in the preceding sections. It must, however, be appreciated that these cases - even with the addition of others that may have escaped reporting - must represent a very insignificant proportion of the vast call-up for the three services during the war years. Coronary disease at or below 35 is, in fact, a very rare event. In 1946 the deaths from this cause in England and Wales under age 35 were $69(0 \cdot 37 \%)$ among 18,800 male deaths and $12(0 \cdot 12 \%)$ among 9,780 female deaths from coronary disease. Where extraneous factors in early life are far to seek it may possibly be shown that genetic influences play a more important part than habits of life and work.

\section{HisTORICAL RETROSPECT}

If the evidence here put forward, in the form of joint clinical and epidemiological studies, can be accepted as supporting the probable importance of an occupational type of hazard falling more heavily, and more considerably with the passage of time, upon those sections of the community whose work entails over-exertion of the mind rather than of the body, it would seem proper to enquire into the changing social circumstances and habits of our 
present era and to compare present with past historical experience. It can scarcely be disputed (1) that the proportion of persons in the country who are professionally and intellectually employed has steadily risen since the industrial revolution of the nineteenth century in concert with such factors as increasing mechanization; the urbanization of the population (some 80 per cent of the people of England and Wales now live in urban areas as compared with 50 per cent a hundred years ago); and the extension of educational opportunity to all classes; (2) that the amount of mental work which can be accomplished by an individual in a day has considerably increased in the past century and especially in the last 25 years. The train, the motor car, the aeroplane; the telegraphic, and telephonic and ordinary and air-mail postal services; the competent secretary, the typewriter and the dictaphone-all these may have made the conduct of affairs more possible, but they have also multiplied the number of intellectual operations-all occasioning vascular responses-that can be performed within a given space of time. Competition in many spheres is more intense. Interruptions to concentrated mental work, which tend to give rise to irritation or frustration, also having their well known vascular accompaniments, are probably far more numerous than formerly. Refreshing sleep is more hardly won. Emotions are more consistently repressed than is the case among more primitive or rural peoples. Professional men a hundred years ago were often just as industrious, but the pace and tempo of their work and the knowledge and responsibilities required of them were of a different order. In no calling, perhaps, would the contrasts be found to be greater than in the medical profession which, of all occupations, shows the highest mortality from coronary disease.

\section{SUMMARY}

In the review of the mortality from coronary disease during the past 25 years in England and Wales the following points of interest emerge.

The mortality amongst males and females aged 35 years and upwards in 1945 was 15 times greater than that in 1921 and the annual number of deaths from coronary disease is now approximately 25,000 . $^{*}$

The increments in the age specific death ratio rates for males and females were on the whole very similar, but there is evidence that in the age period 40-55 years the male death-rate was increasing more rapidly than that for females.

Although there was a fair degree of parallelism in the secular trend of the mortality from coronary and myocardial disease between 1921 and 1938, their subsequent statistical history differed, as the former has continued to increase whereas the latter declined. In 1945 the comparative mortality index for myocardial disease was 24 per cent in defect of the 1938 standard for males and 20 per cent for females.

The increase in the coronary disease mortality in the post-war period is unlikely to be wholly due to a transference of myocardial deaths because there is evidence that the coronary death-rate itself was increasing less rapidly in this period than in pre-war years - the actual death-rates at ages in 1945 being smaller than those predicted on the basis of the statistical experience relating to the period 1931-9.

There is evidence of a distinct sex ratio. The male death-rate in middle age is 5 times greater than that for females: subsequently the ratio decreases with increasing age and at age $75+$ it is less than 2 . There is no similar magnitude in sex differentiation for myocardial disease nor is there any definite correlation with age.

The most realistic explanation of this sex difference would be to ascribe it to an occupational or socioeconomic influence. The mortality from coronary disease amongst men aged $45-55$ in Social Class I is nearly 10 times greater than that of wives, and men of this social category are mainly those in professions and business administration, in which the mental stress and strain accruing from their responsibilities is heavy.

The mortality from coronary disease varies in different regions of the country. The significance and meaning of this geographical variation cannot be accurately assessed owing to absence of requisite information on the age and social stratification of the population within each areal unit. This knowledge is necessary because age and social status are important correlates of the mortality from the disease.

The mortality from cerebral vascular disease showed an increase parallel with that for coronary disease up to 1939 .

The findings of the clinical study, making due allowance for its limitations, reveal a general conformity with those of the statistical study, and help to illustrate in a more detailed way some of the conclusions pertaining to possible causal influences. Age of onset has been discussed. It was 50 years or less in one-quarter of the men and one-eighth of the women. The need and some directives for further enquiry into prognosis have been indicated.

Disease of the coronary arteries has, finally, been considered briefly in its historical context and in particular relation to the remarkable social changes

\footnotetext{
* Deaths from angina pectoris and coronary disease in 1947 totalled 33,168.
} 
that have occurred since it was first described 180 years ago.

\section{Conclusions}

The natural history of coronary disease has been discussed on the basis of a statistical study and of clinical experience, and in particular reference to its rising incidence and its social and occupational associations. The effect of multiple cumulative causes has never, perhaps, been sufficiently emphasized in considering the genesis whether of symptoms or of pathological changes. Effort angina induced by walking a given distance often occurs more readily (a) after a meal, (b) on a cold day, (c) in a state of anxiety or fatigue, than in the absence of one or more of these circumstances. Similarly, the buttressing effects of the several factors reviewed in this paper may be regarded as subscribing to the slow genesis of the underlying arterial change. There is nothing pointing to such alternative causal influences as infection or faulty nutrition. The chemical pressor substances that determine the vascular reactions are endogenous and the product of nervous stimulation.

Physicians are properly interested in the possible practical applications of their enquiries. It seems at present remotely unlikely that we shall discover a "cure" for general arteriosclerosis or coronary artery disease-some part of the processes involved being irreversible. In any case, diseases that attain a wide prevalence, having once been relatively rare, should be constantly considered with a view to a better understanding of how their incidence may be reduced-at least in those age-groups that cover the period of active work and citizenship.
No such dramatic answers are here likely to be forthcoming as in the case of a bacterial or nutritional disease, but, even though they be counsels of perfection, we can at least argue that existing conditions of work in many professional and business careers impose strains which, when endured too long, are beyond physiological tolerance and that the conditions thus call for amendment; that members of predisposed families might sometimes be encouraged at an earlier stage, and even in the face. of an activating conscience or ambition, to regulate their lives more rationally; that, in the field of personal hygiene, the organization of holidays, leisure, exercise and pleasurable relaxation is as sensible as attention to sanitary habits and balanced dietaries; and that the detection of hyperpiesia in the earlier phase by periodic health examinations could have value. The fact remains, however, that mental activity, unlike manual labour, cannot be readily limited by legislation or arrested by the clock. For some time to come we are, therefore, likely to witness a high toll of incapacitation and a sustained, perhaps increasing, death-rate from coronary artery disease affecting - and often at the time of their greatest efficiency-some of the more industrious members of the community in both sexes and in all classes, but more especially the male mental workers of the higher socio-economic grades. This trend is likely to continue-the general ageing of the population making its contribution-until such time as our social reorganization is directed in new ways and in better measure to the promotion of healthy living through a more precise physiological and psychological understanding of man and his capacities and a deeper appreciation of his individual and social needs.

\section{REFERENCES}

Cassidy, M. (1946). Harveian Oration. Lancet, 2, 587. McNee, J. W. (1925). Quart. J. Med., 19, 44.

Newman, M. (1946). Lancet, 2, 409.

Registrar-General's Statistical Reviews of England and Wales for the years 1921 to 1946 . H.M.S.O.
Registrar-General's Decennial Supplement, England and Wales (1931), Part IIa. Occupational Mortality. H.M.S.O. 